\title{
Knowledge, attitudes and compliance of poultry workers with preventive measures for avian influenza in Lagelu, Oyo State, Nigeria
}

\author{
Akinola A. Fatiregun, Mobolaji M. Saani. \\ Department of Epidemiology, Medical Statistics and Environmental Health, Faculty of Public Health, College of Medicine, \\ University of Ibadan, Ibadan, Nigeria.
}

\begin{abstract}
Background: Approximately 1.5 million birds have died or been depopulated as a result of avian influenza infection among poultry in Nigeria. In addition, one human fatal case has been reported in the country. This study was aimed at assessing the knowledge of, attitudes to, and compliance with preventive practices for avian influenza infection among poultry workers in a district in Nigeria.

Methodology: A cross-sectional epidemiological study design was conducted using a semi-structured questionnaire administered at interview to obtain information.

Results: A total of 140 poultry workers from 25 poultry farms were interviewed. Their average age was $29.9 \pm 9.6$ years, and the median duration of work activity was 3 years (range 1 to 21 years). Nearly all respondents (92.9\%) had heard about avian influenza, and their main source of information was the mass media. Only $61.4 \%$ correctly defined the infection as a viral infection that occurs in all species of birds. Knowledge of transmission and preventive practices for the infection was varied and incomplete among respondents. The majority (78.6\%) agreed that avian influenza is a serious and preventable disease; however, the perceived risk of infection was moderate. No vaccination of poultry against avian influenza was reported by $98.6 \%$ of respondents, and wearing of personal protective equipment was not a routine practice. Predictors of preventive practice included fewer years in the work $(p=0.049)$, being married $(p=0.01)$, high knowledge score $(p=0.014)$, not being involved in collecting eggs on the farm $(p=0.008)$, and a large population of poultry on the farm $(p=0.002)$.

Conclusion: There is a need to provide effective and coordinated information to poultry workers about avian influenza and the precautions necessary to avoid spreading the virus among poultry and to humans.

Key Words: Avian influenza; poultry workers; knowledge; attitudes; preventive practices.
\end{abstract}

J Infect Developing Countries 2008; 2(2):130-134.

Received 25 October 2007 - Accepted 16 March 2008.

Copyright $\odot 2007$ Fatiregun et al. This is an open access article distributed under the Creative Commons Attribution License, which permits unrestricted use, distribution, and reproduction in any medium, provided the original work is properly cited.

\section{Introduction}

Avian influenza A virus subtype $\mathrm{H} 5 \mathrm{~N} 1$ has caused many human fatalities and continues to pose an increasing pandemic threat [1]. In Africa, the first outbreak within the poultry population was reported in Kaduna State, Nigeria, in February 2006. Since then, the disease has spread within the poultry population to nearly all parts of the country, which has resulted in the death or depopulation of about 1.5 million birds. In January 2007, a confirmed fatal human case was reported in Lagos. With an estimated poultry population of 159 million (60\% backyard), weak veterinary facilities, and weak surveillance of animal health, the country is at risk of continuous spread of the disease in animals and to humans [2].

Although a national communication strategy and contingency plan has been developed to educate at-risk groups including poultry farmers, this has not been implemented, nor have the baseline educational needs been assessed. In addition, the Federal Government's response to the epidemic has not been complemented by similar efforts at lower levels, especially within the Local Government Areas (LGAs). Workers in the poultry industry, who commonly have contact with sick or dying poultry, are an important at-risk group for targeting of preventive health educational programmes. These workers are at increased risk because of their practices of handling and preparation of raw poultry meat and products. This study was aimed at assessing the knowledge of, attitudes to, and compliance with preventive practices for avian influenza infection among poultry workers in an LGA in Nigeria. 


\section{Materials and Methods}

The study was conducted in Lagelu LGA, Oyo State, one of the 774 LGAs in Nigeria (figure 1). The LGA is located in the southwestern geopolitical zone of the country. It is bordered to the north by the Akinyele and Iwo LGAs of Oyo and Osun States, respectively; to the south by the Ona-ara and Ibadan Northwest LGAs of Oyo State; and to the east by the Irewole, Isokan and Ayedire LGAs of Osun State. It has a total human population of approximately 200,536 , and a land mass area of approximately $862 \mathrm{sq} \mathrm{km}$, of which $70 \%$ is rural. Part of the Ibadan metropolis, the capital of Oyo State constitutes the major urban component of the LGA. The poultry industry is a significant component of the income-generating activity of the LGA. This LGA was purposely selected because of the high concentration of poultry farmers who produce and market poultry from this area of Oyo State [3].

Figure 1. Map of Nigeria showing the location of Lagelu Local Government Area.

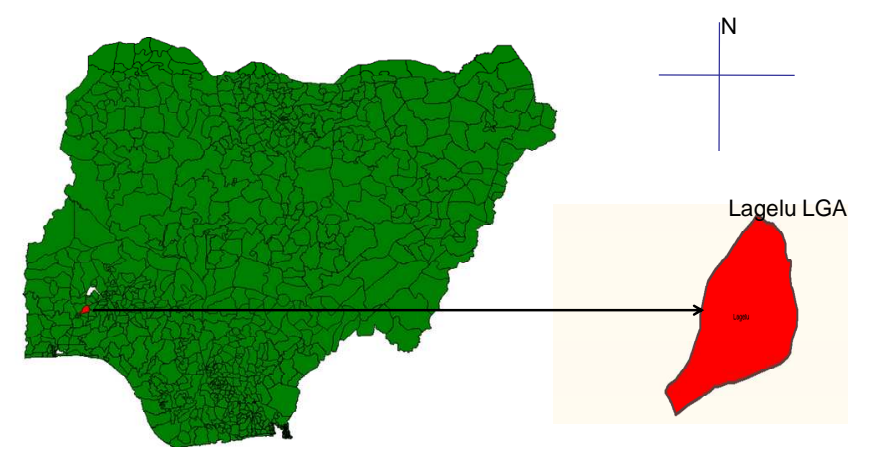

A cross-sectional epidemiological study design was employed using a pretested, semi-structured questionnaire administered at interview. The questionnaire was pretested on 20 poultry workers from a farm in the Ibadan North LGA of Oyo State in August 2007. Twenty-five farmyards were identified through the records of the Department of Agriculture of Lagelu LGA and by "snowballing." Visits were scheduled and were made to the poultry farms on week days during September 2007. All poultry workers on each farm who were met at the time of the visit were interviewed, after permission had been obtained from both the head of the farm and the workers themselves. Using the questionnaire, information about demographics, work activity, knowledge of the transmission and prevention of avian influenza, attitudes towards the disease, and compliance with precautions at work were obtained from each participant.

The data were entered into a computer using Epi-Info 2000 software version 3.3.2 [4]. Interactive validation was performed using the "check file" submenu. After data cleaning, frequencies were obtained for all variables; medians or means and standard deviations or ranges were computed for continuous variables. Knowledge and practice scores were computed by addition of scores from the variables pertaining to these items. There were 55 questions (variables) related to knowledge and 30 questions on practice. A correct response to an item attracted a score of 1 , while an incorrect response attracted a score of 0 . This gave maximum scores of 55 and 30 for the knowledge and practice variables, respectively. Multivariate linear regression analysis was used to evaluate predictors of both the knowledge and practice scores.

\section{Results}

A total of 140 poultry workers were interviewed, with a median number of respondents of 4 and a range of 1 to 29 workers interviewed on each farm. The average age of respondents was $29.9 \pm 9.6$ years; $58 \%$ of the respondents were male. About half the respondents were single and had never married, while the majority $(70 \%)$ had attended at least a high school. The median duration of work on a poultry farm was 3 years, with a range from 1 to 21 years. The number of birds on each farm varied from 200 to 25,000 , with a median of 5,000 birds. The most common types of poultry-related work performed by the respondents were feeding of poultry $(82.1 \%)$, sweeping/packing of poultry droppings (65.7\%), and collecting eggs (62.9\%) (Table 1$)$.

Nearly all the respondents $(92.9 \%)$ had heard about avian influenza infection; with the majority $(74.3 \%)$ reporting mass media (television, radio and newspapers) as their main source of information (Table 2). However, only $61.4 \%$ of respondents correctly defined avian influenza infection as a viral infection that occurs in all species of birds. Knowledge of transmission of the disease varied: $72.9 \%$ knew that the disease could be transmitted from bird to bird, and 55\% knew it could be transmitted from bird to human and through handling of uncooked poultry. Only $14 \%$ 
suggested the possibility of human to human transmission. Regarding preventive measures, $65.7 \%$ knew that wearing a facemask, overalls (67.9\%), boots or boot covers $(64.3 \%)$, and eye protection (57.9\%) are measures that may prevent the spread of the disease. Other preventive measures reported by respondents were washing and disinfecting surfaces/body (84.3\%), and vaccination of birds (67.9\%). Multiple linear regression analysis of the total knowledge score revealed that using mass media $(p=0.002)$ and employers $(p=0.011)$ as sources of information were predictors of knowledge.

Table 1. Types of work performed by poultry workers.

\begin{tabular}{lc}
\hline Type of work & Frequency; $\mathbf{n = 1 4 0}(\%)$ \\
\hline Feed poultry & $115(82.1)$ \\
Collect eggs & $88(62.9)$ \\
Sweep and pack poultry droppings & $92(65.7)$ \\
Slaughter and defeather poultry for sale & $24(17.1)$ \\
Guard the poultry environment & $13(9.3)$ \\
Supervision & $44(31.4)$ \\
\hline$p<0.001$ &
\end{tabular}

The majority of respondents (78.6\%) agreed that avian influenza is a serious and preventable disease. On a scale of 1 (no fear of getting disease) to 10 (fear of getting disease), the median rating of fear of getting the disease was 5 (range 1 to 10 ). Only $29.3 \%$ had modified their behaviour regarding the handling of birds and poultry products in the past 6 months. The majority (81\%) thought that they needed more information about the disease.

Table 2. Sources of information reported by poultry workers.

\begin{tabular}{lc}
\hline $\begin{array}{l}\text { Sources } \\
\text { of information }\end{array}$ & $\begin{array}{c}\text { Frequency; } \\
\mathbf{n = 1 4 0}(\%)\end{array}$ \\
\hline Mass media (television, radio, newspapers) & $104(74.3)$ \\
Friends/family members & $38(27.0)$ \\
Employer & $29(20.7)$ \\
Health professionals & $13(9.3)$ \\
Internet & $10(7.1)$ \\
School & $10(7.1)$ \\
Poultry workers' association. & $11(7.9)$ \\
\hline p<0.001.
\end{tabular}

Regarding compliance with preventive practices, no vaccination of poultry was reported by $98.6 \%$ of the respondents. The reasons reported for this included unavailability of vaccines $(37 \%)$ and lack of veterinary services (43.6\%). Only $11.4 \%$ reported that they always used a facemask, gloves (10.7\%), boots or boot covers $(16.4 \%)$ and eye protection (0.7\%). However, the majority $(81.4 \%)$ reported always washing their hands and wearing outer protective garments $(60 \%)$. The multiple linear regression analysis of the practice score showed that fewer years at work $(p=0.049)$, being married $(p=0.010)$, high knowledge score $(p=0.014)$, collecting eggs $(p=$ 0.008 ), and a large number of poultry on the farm $(p=0.002)$ were significantly associated with compliance with preventive measures against avian influenza infection (Table 3).

Table 3. Linear regression model: preventive practice score used as dependent variable.

\begin{tabular}{lccc}
$\begin{array}{l}\text { Independent } \\
\text { variable }\end{array}$ & $\boldsymbol{\beta}$ coefficient & $\mathbf{t}$ & $\mathbf{p}$-value \\
\hline $\begin{array}{l}\text { Number of years } \\
\text { of work }\end{array}$ & $-1.5 \mathrm{E}-03$ & -1.994 & 0.049 \\
Marital status & 0.810 & 2.610 & 0.010 \\
Knowledge score & $8.806 \mathrm{E}-02$ & 2.496 & 0.014 \\
Collect eggs & -0.820 & -2.701 & 0.008 \\
Number of poultry & $7.847 \mathrm{E}-05$ & 3.228 & 0.002 \\
Constant & 2.419 & 3.626 & $<0.001$ \\
\hline F=5.353; $\mathrm{p}<0.001 ; \mathrm{R}^{2}=19.7 \% ;$ adjusted $\mathrm{R}^{2}=16 \%$. & &
\end{tabular}

\section{Discussion}

The limitation that the study setting imposed on the design of the current study is recognized. Many farms were not registered with the LGA Agriculture Department; hence it was not possible to select poultry farms by simple random sampling. We had anticipated that the sampling frame from the Agriculture Department would be the basis of our sampling process, but were forced to identify poultry farms largely by "snowballing." Records were not kept properly on many of the poultry farms visited; hence it was difficult to obtain a list of workers from which to recruit study participants. Also, as documented by a previous study in the same LGA [3], participation in the farmers' association is low, which made it difficult to contact more farms within the study period.

The data on poultry worker demographics indicated that poultry workers were generally young adults and the majority were male. This is consistent with the findings of Fawole (2006) in the same LGA [3], who reported an average age of 36 years in farmers who participated in a study on the utilization of information. Abbate et al. (2007) [5] reported an average age of 40 years among a sample of poultry workers who were assessed on their knowledge, attitudes and practices with respect to avian influenza in Italy. As expected, poultry workers in the current study were involved 
in daily activities that caused them to be in close contact with birds and their products; hence they were at increased risk of transmission of the pathogen.

Although awareness of avian influenza infection was high among the poultry workers studied here, knowledge of the infection, its transmission, and appropriate preventive measures was variable and incomplete. This is similar to the findings of Abbate et al. (2007) [5]. However, in the present study, while knowledge was greater in workers with more education, those who had worked for a longer time in the industry, those who believed they were at high risk of contracting avian influenza, and those who requested more information, only the source of information was significantly associated with the overall knowledge score. Those who had reportedly heard about avian influenza through the mass media and from their employer tended to have a more complete knowledge of the infection than those who had obtained information from other sources. This suggests the need for a scaling up of information sources through posters, handbills, seminars, etc. to reach the poultry workers in the LGA.

The perception of risk by respondents in this study was higher than that reported by Abbate et al. [5]. Also, the respondents indicated the need for more information regarding the infection. These positive attitudes stand to reinforce any focused health education programme.

In agreement with the findings of Abbate et al. [5], wearing of personal protective equipment was not a routine practice among the group studied here. Also, vaccination against avian influenza was not being provided for poultry birds. Worst still, the systems for disposal of waste were poor. These are gaps which health education programmes should target. Compliance with preventive measures was found to be significant among those who were more recently employed in the industry. This may be because, after some years on the job, workers felt that they were immune to the risk of infection and may not have appreciated the need to comply. In addition, those who were married complied with preventive measures more thoroughly than those who were unmarried. Married people are generally more secure and protected, and they usually lead a more sober life than those who are not married [6]. The finding that compliance with safety measures was increased on farms with a larger population of poultry may reflect the management capability of such farms. Large farms are likely to be better organized than small farms; hence, standards are enforced and followed. The finding that those with greater knowledge are more likely to comply than to those with little knowledge, and that those involved in collecting eggs are less likely to comply with preventive measures than those not involved in such work is consistent with the results of a previous study [5]. In that report, preventive practices were more common in poultry workers who knew that these measures were protective, and less common in workers who handled only eggs.

In conclusion, this study has identified gaps in the knowledge of and compliance with preventive practices among poultry workers in the Lagelu LGA of Oyo State, Nigeria. The need to provide effective and coordinated information about avian influenza and the necessary precautions to avoid spreading the virus among poultry and humans cannot be overemphasized [7]. It is suggested that compliance with preventive measures may be enhanced through behavioural modification. To facilitate the coordination of these interventions, however, there is a need to encourage the participation of farmers in farmers' associations and the registration of farms should be available at low cost. Scaling up of information sources to farmers is one of the strategies that will require proper planning, monitoring and evaluation.

\section{References}

1. The Writing Committee of the World Health Organization (WHO) Consultation on Human Influenza A/H5 (2005) Avian influenza A (H5N1) infection in humans. N Engl J Med. 353:1374-85.

2. Coker EBA (2007) Update on Avian Influenza in Nigeria: National Response and Challenges. A presentation of the Federal Ministry of Health (FMOH) at a surveillance training programme for State Epidemiologists held in Enugu.

3. Fawole OP (2006) Poultry Farmers' Utilization of Information in Lagelu Local Government Area, Oyo State of Nigeria. Intl J Poultry Sci. 5 (5): 499-501.

4. Dean AG, Arner TG, Sunki GG, Friedman R, Lantinga M, Sangam S, Zubieta JC, Sullivan KM, Brendel KA, Gao Z, Fontaine N, Shu M, Fuller G (2002) Epi InfoTM, a database and statistics program for public health professionals. Centers for Disease Control and Prevention, Atlanta, Georgia, USA.

5. Abbate R, Di Giuseppe G, Marinelli P, Angelillo IF (2006) Knowledge, attitudes, and practices of avian influenza, 
poultry workers, Italy. Emerg Infect Dis [serial on the Internet]. 2006 Nov [date cited]. Available from http://www.cdc.gov/ncidod/EID/vol12no11/06-0671.htm.

6. Park K (2000) Principles of Epidemiology and Epidemiologic Metthods In: Park K, Park`s Textbook of Preventive and Social Medicine 16th eds. Jabalpur, India: $\mathrm{M} / \mathrm{s}$ Banarsdas Publishers.

7. World Health Organization (2006) Public health interventions for prevention and control of avian influenza. A manual for improving biosecurity in the food supply chain: focusing on live animal markets. New Delhi: Regional Office for South-East Asia.
Corresponding Author: Akinola A Fatiregun, Department of Epidemiology, Medical Statistics and Environmental Health, Faculty of Public Health, College of Medicine, University of Ibadan, Ibadan, Nigeria. Email akinfati@yahoo.com

Conflict of interest: No conflict of interest is declared. 